\title{
Open water integrated multi-trophic aquaculture: constraints on the effectiveness of mussels as an organic extractive component
}

\author{
Peter J. Cranford ${ }^{1, *}$, Gregor K. Reid ${ }^{2}$, Shawn M. C. Robinson ${ }^{2}$ \\ ${ }^{1}$ Fisheries and Oceans Canada, Bedford Institute of Oceanography, 1 Challenger Dr., Dartmouth, Nova Scotia B4C 4C9, Canada \\ ${ }^{2}$ Canadian Integrated Multi-Trophic Aquaculture Network (CIMTAN), University of New Brunswick, PO Box 5050, \\ Saint John, New Brunswick E2L 4L5, Canada
}

\begin{abstract}
Mussels are currently the primary species employed in open water integrated multitrophic aquaculture (IMTA) systems to extract particulate organic fish waste (OFW) exiting fish net-pens. Information on mussel feeding and digestion physiology was used to identify constraints on the capacity of mussels to capture and absorb OFW under various open water IMTA scenarios. OFW capture by mussels is severely limited by the time available to intercept solid wastes contained in the horizontal particle flux. Intensive and spatially extensive mussel culture within IMTA systems could improve waste extraction, but maximum efficiency will ultimately be constrained by current velocity, available IMTA farm space, and any negative feedback effects on fish culture from flow reduction caused by mussel culture. The ability of mussels to absorb more of the ingested organic fish feces (OFF) than they egest as mussel feces (a waste biomitigation requirement) depends on the concentration of OFF available to mussels, relative to the ambient seston concentration and seston organic content. The biomitigation potential of mussels will be greatest where seston abundance is low and the organic content is high. Achieving maximum waste extraction by mussel co-culture entails depleting their particulate food supply to a level that may limit mussel production. Consequently, a constraint on waste extraction may be the desire to maximize profits from the extractive species. This study identified important constraints on the capacity of mussels to perform their intended role in IMTA systems that can only be partially addressed by optimizing system design.
\end{abstract}

KEY WORDS: Integrated multi-trophic aquaculture - Organic fish waste $\cdot$ Mussel physiology · Biofiltration · Biomitigation · Organic enrichment

\section{INTRODUCTION}

Sustainable aquaculture is a complex and abstract concept with the objectives of being ecologically efficient, environmentally benign, profitable, and societally beneficial in the long term. Open water integrated multi-trophic aquaculture (IMTA) systems have been promoted as sustainable and practical

*Email: peter.cranford@dfo-mpo.gc.ca alternatives to caged-fish monoculture that could help to fulfill the growth potential of aquaculture (Chopin et al. 2001, Troell et al. 2003). IMTA involves cultivating several species from different trophic levels in a manner that allows one species' wastes (uneaten feed and/or by-products) to be recaptured or converted into a resource that is utilized by other species in the system. This approach exploits natural

(C) Reid, Robinson and Fisheries \& Oceans Canada 2013. Open Access under Creative Commons by Attribution Licence. Use, distribution and reproduction are unrestricted. Authors and original publication must be credited.

Publisher: Inter-Research · www.int-res.com 
synergistic interactions between cultured species to biomitigate some of the wastes produced while also increasing farm profits. Although more sophisticated and diversified IMTA systems are foreseen, existing systems currently operating in open water conditions are relatively simple and involve seaweeds to assimilate and extract dissolved nutrients, filter-feeders (primarily bivalves) to exploit suspended particulate organic materials, and deposit-feeders to use solids that settle below fish cages (Soto 2009).

The design and optimization of IMTA systems require assessments of the efficiency of the various culture species to intercept and assimilate the targeted waste stream and thereby reduce known impacts. It is also important to take a holistic approach to system design to ensure that desired interactions between species are not overly constrained by environmental dependence or cause other detrimental effects. Optimizing synergies between the various crop species requires an advanced understanding of aquaculture-ecosystem dynamics, both in general as well as for specific aquaculture sites. Mussels are currently the primary organic extractive component used in open water IMTA systems (Soto 2009). Commercial mussel species occupy a wide geographic distribution and can be cultured in dense populations and at relatively high biomass. These traits make them ideal candidates as particulate waste biofilters. Mussel population filtration rates can reach levels known to seriously deplete suspended particulate matter and control phytoplankton production at the coastal ecosystem scale (e.g. Grant et al. 2008, Dame 2011). This is a desirable attribute within an IMTA context given that particulate organic fish waste (OFW) interception and recycling is the primary role of these mussels.

Mussel feeding and digestion physiology has been extensively studied, and this predictive knowledge was used in the present study to estimate the potential efficiency of suspended mussel crops to intercept waste particles under present and alternative open water IMTA scenarios. This analysis of integrated fish-mussel culture systems expands on the previous modeling efforts of Troell \& Norberg (1998) by providing estimates of OFW extraction efficiency as a quantitative metric for assessing and optimizing IMTA environmental performance. An analysis of the production of particulate organic waste products by mussels (feces originating from the ingestion of fish waste solids and natural seston) was also conducted to examine the net balance between the beneficial effects of fish waste absorption by mussels and the potential adverse effects of mussel fecal deposition.

\section{WASTE PARTICLE CAPTURE EFFICIENCY}

Mussels are currently held within IMTA systems using animals stocked on 'droppers' (mesh socks or ropes) that are hung from rafts or rope longlines. A critical process in the extraction of particulate organic wastes by IMTA mussels is particle capture. We assessed the efficiency of this process by comparing the horizontal flux of OFW particles through a $1 \mathrm{~m}^{2}$ vertical plane of water column, with the predicted ingestion flux by a given population of mussels contained within the same vertical area. These fluxes $\left(\mathrm{g} \mathrm{m}^{-2} \mathrm{~h}^{-1}\right)$ may be scaled to estimate particle capture efficiency. Horizontal particle flux $(P)$ was calculated for a range of current speeds $(u)$ from 2 to $8 \mathrm{~cm} \mathrm{~s}^{-1}$ and a particle concentration $(C)$ of $1 \mathrm{mg}$ dry weight $(\mathrm{DW}) \mathrm{l}^{-1}(P=u \times C)$. The $2 \mathrm{~cm} \mathrm{~s}^{-1}$ minimum current speed corresponds with the threshold at which pre-harvest salmon cultured in the Bay of Fundy, Canada, are predicted to deplete oxygen inside net-pens below adequate levels ( $u$ below threshold for more than $40 \mathrm{~min}$; Page et al. 2005). The particle concentration used in the calculations was arbitrarily set, as it has no effect on the scaling results (see below). Mussel ingestion flux $(I)$ was calculated as follows for a population $\left(N_{\text {; }}\right.$ ind. $\left.\mathrm{m}^{-2}\right)$ of between 100 to 1000 commercial size animals ( $0.7 \mathrm{~g}$ dry tissue weight) contained within the $1 \mathrm{~m}^{2}$ vertical plane of water column:

$$
I=C R \times N \times C
$$

where clearance rate $(C R)$ is set at $2.441 \mathrm{~h}^{-1}$ for a $0.7 \mathrm{~g}$ DW mussel (average value for mytilid species of commercial size; Cranford et al. 2011). MacDonald et al. (2011) reported an average $C R$ of $2 \mathrm{l} \mathrm{h}^{-1}$ for $60 \mathrm{~mm}$ shell length mussels feeding on fish feed. This value is lower than was reported for similar sized mussels feeding on natural seston $\left(3.2 \mathrm{l} \mathrm{h}^{-1}\right.$; Cranford et al. 2011). However, given that the diets are mixed under natural conditions, the above average rate from Cranford et al. (2011) was used. Mussel densities used in calculations reflect a range of low to high stocking densities employed by the mussel culture industry. The upper limit of 1000 ind. $\mathrm{m}^{-2}$ would equate to 5 dropper sections (each $1 \mathrm{~m}$ long), spaced $20 \mathrm{~cm}$ apart and each holding 200 mussels. Capture efficiency $(E)$ was calculated as:

$$
E(\%)=I / P \times 100
$$

Note that $C$ cancels out in Eq. (2), and any concentration value selected is mathematically immaterial to the results. In nature, mussel $C R$ can be responsive to changes in $C$ and $u$, but both effects tend to be 
minimal for the range of conditions employed in this analysis. Eqs. (1) \& (2) do not account for the expected satiation of total particle intake at some maximum food concentration or for the effects of preingestive particle selection on food intake by mussels. Maximum ingestion rate and the initiation of biologically significant food rejection occurs in mussels at relatively high particle concentrations (>10 mg l${ }^{-1}$; e.g. Hawkins et al. 1998, 1999) compared with levels observed at IMTA sites investigated in Canada, Norway, and the Mediterranean (Lander et al. 2004, Sarà et al. 2009, Reid et al. 2010, MacDonald et al. 2011, Handå et al. 2012a). The following analysis is therefore meant to be applicable to similar environments. Particle selection is considerably less predictable than particle capture given conflicting data on mussel responses to increasing diet concentrations (Ward \& Shumway 2004) and the lack of any studies on the selection or rejection of fish wastes by mussels. These additional processes should be considered in more complex modeling exercises.

The results of the flux scaling analysis for a single mussel culture unit (e.g. a longline arranged perpendicular to the flow direction to support mussel droppers) intercepting waste particles flowing from fish net-pen(s) show that particle capture efficiency is severely limited by the time the mussels have to filter the water. Even at the relatively slow current speed of $2 \mathrm{~cm} \mathrm{~s}^{-1}$, the highest mussel density was only capable of capturing $3.5 \%$ of particles in the horizontal flux (Fig. 1A). At current speeds of 4 and $8 \mathrm{~cm} \mathrm{~s}^{-1}$, maximum capture efficiency is reduced to 1.7 and $0.9 \%$, respectively (Fig. 1A). The number of culture units needed to reach $50 \%$ particle capture efficiency, which was selected as an arbitrary example to further describe the potential waste recycling capacity of IMTA, was subsequently calculated $(=50 / E)$, and the results are shown in Fig. 1B. At minimum current speeds of $2 \mathrm{~cm} \mathrm{~s}^{-1}, 15$ high-density mussel culture units would be needed to capture half the OFW particles that pass the mussel droppers. This increases to 60 culture units at $8 \mathrm{~cm} \mathrm{~s}^{-1}$. These calculations indicate that the mussel culture component of an open water IMTA system would need to be intensive (high standing stock on numerous culture structures) even under conditions of relatively low current speeds, to reach an arbitrary target of $50 \%$ waste capture from the horizontal flux.

One consequence of suspended mussel culture is that the drag exerted on water flow by the farm structures results in flow reduction (e.g. Strohmeier et al. 2005). Flow reduction may permit particulate wastes to settle closer to the fish pens such that waste parti-
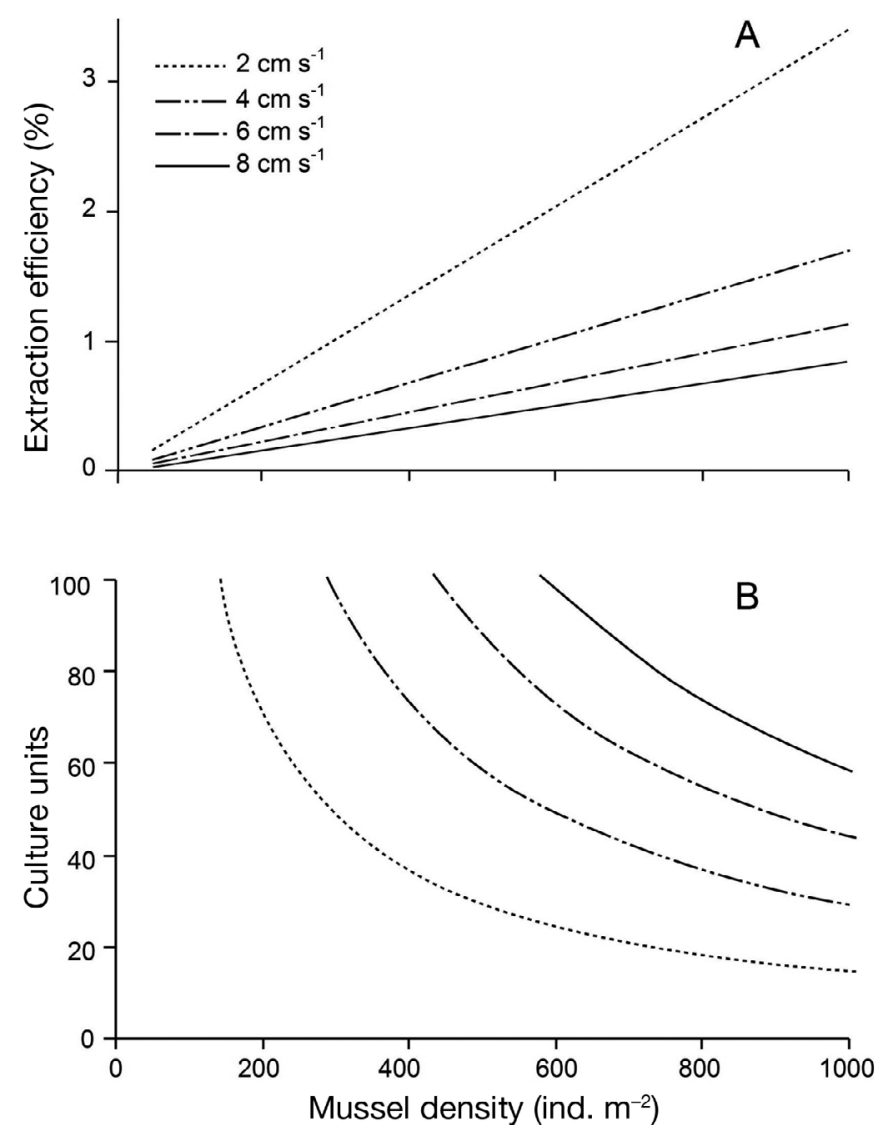

Fig. 1. (A) Efficiency of particle capture by commercial size mussels for a range of current speeds and animal densities within a $1 \mathrm{~m}^{2}$ vertical plane of water column. (B) Number of consecutive culture units (see description under 'Waste particle capture efficiency' in the main text) needed to reach $50 \%$ capture efficiency for the given ranges of current velocities and mussel densities

cles are less available to mussels in surface waters, but could also be advantageous from the perspective that waste particle capture by mussels will be more efficient at the farm-induced lower current speeds (Fig. 1). High levels of flow reduction and feedback effects on food depletion (increased) and mussel growth (decreased) have been observed and predicted for mussel longline and raft farms (reviewed by Rosland et al. 2011). Persistent farm-induced flow reduction may also have undesirable effects in an IMTA situation if the presence of intensive culture structures reduced current flow to adjacent fish netpens to levels below the threshold $\left(2 \mathrm{~cm} \mathrm{~s}^{-1}\right.$ for more than $40 \mathrm{~min}$ ) needed to maintain adequate oxygen in net-pens (>6 mg O $\mathrm{Ol}_{2} \mathrm{l}^{-1}$; Page et al. 2005). Similarly, Remen et al. (2012) reported that $60 \% \mathrm{O}_{2}$ saturation was a minimum requirement for the welfare of postsmolt Atlantic salmon exposed to cyclic hypoxia. Cur- 
rent speeds below the $2 \mathrm{~cm} \mathrm{~s}^{-1}$ threshold already occur intermittently near IMTA operations in the Bay of Fundy (Page et al. 2005), and the possible expansion of mussel culture operations at these sites should be conducted in a way that avoids increasing the exposure of fish to sub-optimal dissolved oxygen conditions.

The above waste capture efficiency estimates are based on a conservative (i.e. best-case) scenario and are expected to be overestimated for several reasons. First, the mussels would not be evenly distributed over the water column, but are clustered on the droppers. This may allow a large fraction of the particle flux to pass between the droppers out of the reach of mussel feeding currents. Alternatively, turbulent flows induced by the structures may improve particle contact with mussel feeding currents. Second, the clustering of mussels on the droppers allows re-filtration of water as it passes multiple animals, and this would mean that the population clearance rate employed in the above calculations was overestimated. Third, the mussels used in these calculations are of harvestable size, and population clearance rates may be considerably lower during earlier stages of culture. Fourth, we are assuming that all fish waste particles can be captured by mussels with equal efficiency. While mussels are highly opportunistic feeders that can effectively capture a wide size range of particles ( $\sim 3$ to $6000 \mu \mathrm{m}$; Davenport et al. 2000, Ward \& Shumway 2004), the capacity to ingest large waste feed particles and fish feces present in the horizontal particle flux may be much lower than assumed in this analysis. Lastly, for mussels to reach the indicated fish waste capture efficiencies, their holding structures would have to be placed within transport pathways for all particulate OFW exiting the net-pens at all stages of the tidal cycle. Currently, mussels are confined mainly to surface waters (ranges from 5 to $13 \mathrm{~m}$ depth with most mussels held at $<7 \mathrm{~m}$ depth; S. M. C. Robinson pers. obs.) in relatively small areas outside open water IMTA farms. This spatial arrangement of mussels limits their waste exposure to specific tidal periods and primarily to 'unsettleable' particulate wastes known as 'fines' that originate from fish pellets. Uneaten feed pellets and relatively large fish feces may exit net-pens below the mussels and may not be of a suitable size for ingestion by filter-feeders. The high degree of waste 'leakiness' at current open water IMTA sites, combined with the limited efficiency of the mussel biofiltration system under typical flow conditions, results in a low fraction of the solid organic fish waste flux being captured by these filterfeeding species.

\section{BIOMITIGATION POTENTIAL}

The feeding activity of dense populations of mussels can be a significant factor in the transformation and translocation of suspended particulate matter in the marine environment (Dame 2011). Their role in altering particle transport results from the consumption of relatively fine suspended particles (e.g. phytoplankton, zooplankton, detritus), and the subsequent production of fecal pellets that exhibit much higher settling velocities. Not all of the organic matter contained in ingested salmon feces and waste feed (77 and $93 \%$ organic, respectively; Reid et al. 2010) is extracted in the mussel harvest. An average of $10 \%$ from the fish feed and $14 \%$ of the salmon feces organic matter consumed by mussels may be egested as feces (Reid et al. 2010), and this loss term needs to be factored into the overall determination of IMTA waste extraction efficiency. Although the consumption of waste feed fines may contribute to mussel production in IMTA systems, extraction of these organic wastes in the mussel harvest has no known beneficial effect because the feed fines are considered 'unsettleable' and therefore do not contribute to local benthic organic enrichment impacts at fish farms. The transformation of some of this organic material into mussel fecal pellets that settle at an average velocity of $1.0 \mathrm{~cm} \mathrm{~s}^{-1}$ (Weise et al. 2009) may contribute to benthic organic loading near fish net-pens. Organic matter in fish feces is largely responsible for the benthic habitat and community impacts of open water fish aquaculture, and the transformation of some of this material into mussel biomass, which is subsequently harvested, could theoretically reduce benthic organic loading under IMTA systems compared with fish monoculture sites (Soto 2009). Consequently, the following analysis of the biomitigation capacity of mussels focuses on the organic fish feces (OFF) component of total OFW.

Natural food sources are an important dietary component for IMTA mussels and are critical from the perspective of determining whether the mussels actually realize their intended role of reducing benthic impacts from fish feces deposition. This benefit would occur only if the absorption rate of organic matter in fish feces $\left(A_{\mathrm{OF}} ; \mathrm{g} \mathrm{h}^{-1}\right)$ by mussels was greater than their organic matter egestion rate $(F)$. This fundamental requirement of any organic extractive species may be expressed in the form of the following 'biomitigation indices' $(B I)$ :

$$
\begin{gathered}
B I_{1}=A_{\mathrm{OF}} /\left(F_{\mathrm{OF}}+F_{\mathrm{OS}}\right) \\
B I_{2}=A_{\mathrm{OF}} / F_{\mathrm{OS}}
\end{gathered}
$$


Mussel egestion rates include organic matter from undigested fish feces $\left(F_{\mathrm{OF}}\right)$ and from natural seston $\left(F_{\mathrm{OS}}\right)$. Index values greater than unity represent desirable IMTA conditions where the mussels are predicted to absorb more waste organic matter than they release as feces (i.e. a biomitigation potential is indicated). The first index includes both natural and anthropogenic feces constituents and estimates the net balance between waste absorption and total organic egestion that results from ingesting a mixed diet. The second index excludes the defecation of undigested organic matter in fish feces because the organic matter contained in $F_{\mathrm{OF}}$ would be present at a fish farm even if mussels were not present, albeit in a different particulate form. Consequently, the biomitigation potential of IMTA mussels may best be indicated by $\mathrm{BI}_{2}$. To investigate possible dietary conditions under which biomitigation by mussels is indicated, the 2 indices were calculated for a $0.7 \mathrm{~g} \mathrm{DW}$ mussel using a range of natural seston concentrations (0 to $10 \mathrm{mg} \mathrm{DW}^{-1}$ ) combined with different levels of solid fish feces $\left(0.1\right.$ to $\left.5.0 \mathrm{mg} \mathrm{l}^{-1}\right)$. Given that mussels are generally cultured outside of fish farm cage arrays, the fish waste component was estimated to be available to mussels $50 \%$ of the time. This assumes that bidirectional changes in tidal flow alter the availability of fish wastes to the mussels. The organic content (OC) of fish feces was set at $77 \%$ and the corresponding mussel absorption efficiency $(A E)$ at $86 \%$ (Reid et al. 2010). To examine the effects of different seston and waste concentrations on $B I_{1}$ and $B I_{2}$, seston was initially assumed to be $40 \%$ organic (typical value observed by the authors at IMTA farms in the Bay of Fundy) with an average $A E$ of 0.46 , which was estimated using:

$$
A E=0.9 \times\left(1-\mathrm{e}^{[-3.6 \times(\mathrm{OC}-0.2)]}\right)
$$

Eq. (5) was derived to estimate average mussel $A E$ values at different dietary OCs based on relationships reported by Bayne et al. (1987), Navarro et al. (1991, 1996), Figueiras et al. (2002), and Reid et al. (2010). This equation was also used to examine effects on $B I_{1}$ and $B I_{2}$ resulting from the presence of a wide range of seston OCs. The average mussel clearance rate given above was employed along with these $A E$ estimates to calculate rates of organic ingestion $(I=C R \times C)$, absorption $(A=I \times A E)$, and egestion $(F=I-A)$ for each seston and waste dietary concentration. These data were then used to calculate both biomitigation indices.

Biomitigation index calculations suggest that mussels have the capacity to reduce organic enrichment effects from OFF under specific aquaculture condi- tions. These conditions are defined by the concentration of OFF available to mussels, which affects $A_{\mathrm{OF}}$ and $F_{\mathrm{OF}}$, and the ambient seston concentration and OC, which affect $F_{\text {OS }}$. The interacting effects of fish waste and seston concentrations on the biomitigation potential of mussels are illustrated in Fig. 2. In areas where seston concentrations are relatively low, OFF will tend to comprise a relatively high percentage of the particulate organic matter ingested by mussels, and the resulting waste absorption rate can potentially exceed organic egestion rates (BI $\geq 1$; Fig. 2). In IMTA systems characterized by high seston conditions, high OFF concentrations are needed to allow the waste absorption rate to exceed the relatively high seston egestion rate (Fig. 2). The OFF percent-

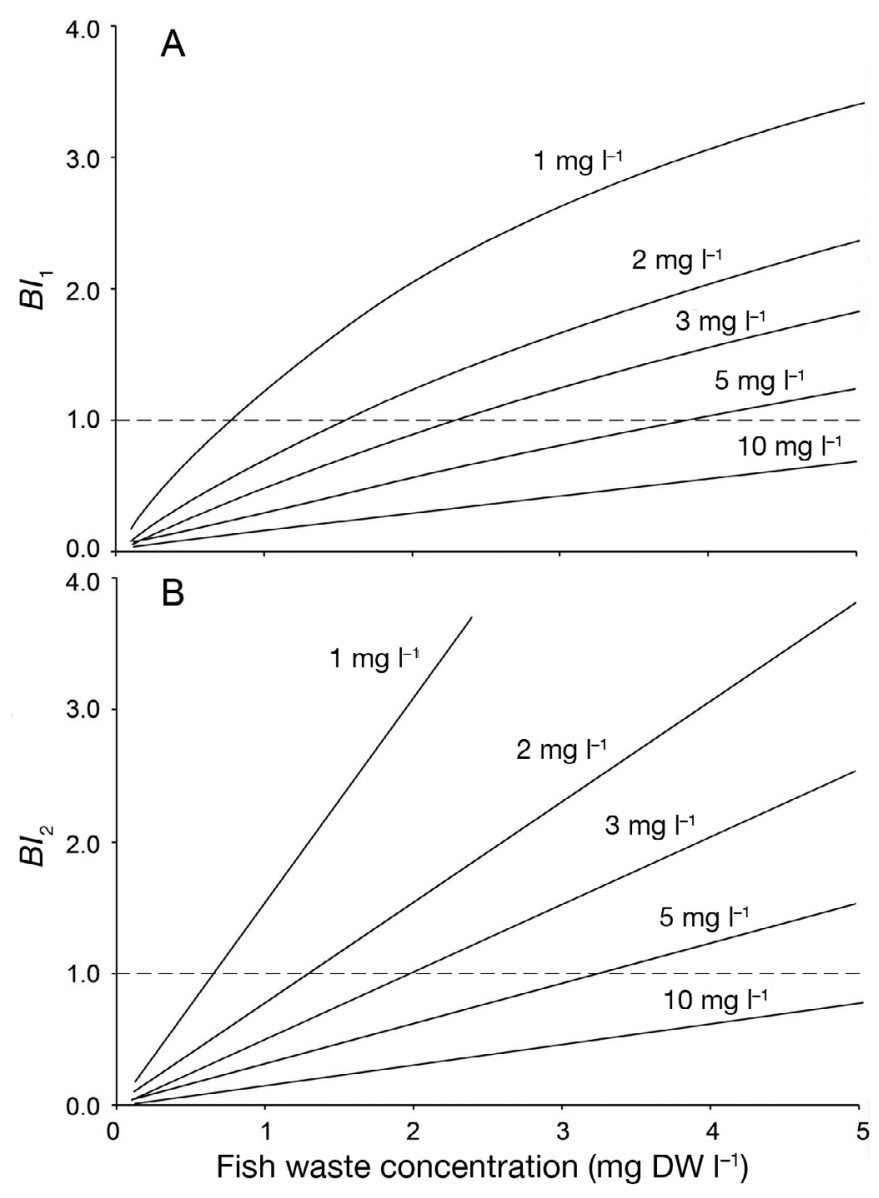

Fig. 2. Relationships between suspended fish waste dry weight (DW) concentration and the 2 mussel biomitigation indices (see Eqs. $3 \& 4$ under 'Biomitigation potential' in the main text). The different lines show results for seston concentrations of $1,2,3,5$, and $10 \mathrm{mg} \mathrm{DW} \mathrm{m}^{-1}$, assuming 77 and $40 \%$ organic contents for the fish waste and seston, respectively, and wastes are available $50 \%$ of the time. A biomitigation index $(B I)$ less than unity (dashed line) represents non-biomitigation conditions where mussels produce more organic wastes as feces than they absorb from the ingested fish wastes 
age of total organic matter ingested by mussels is therefore an important parameter for assessing the biomitigation potential of mussels at IMTA sites. The required diet proportions permitting biomitigation are also affected by seston OC, as illustrated in Fig. 3. In the modeled scenario, where seston OC was assumed to be $40 \%$ (e.g. IMTA farms in the Bay of Fundy), $B I_{1}$ and $B I_{2}$ exceeded the biomitigation threshold value of 1 when ingested organic matter consisted of more than 30 and $28 \%$ OFF, respectively (Fig. 3). At sites where seston OC is higher, the seston is absorbed more efficiently by mussels and the required OFF proportion decreases (Fig. 3). In contrast, IMTA sites located in areas with low seston nutritional quality are less suitable for employing mussels for waste biomitigation purposes. Both biomitigation indices provided somewhat similar results (Figs. 2 \& 3) because OFF has been reported to be

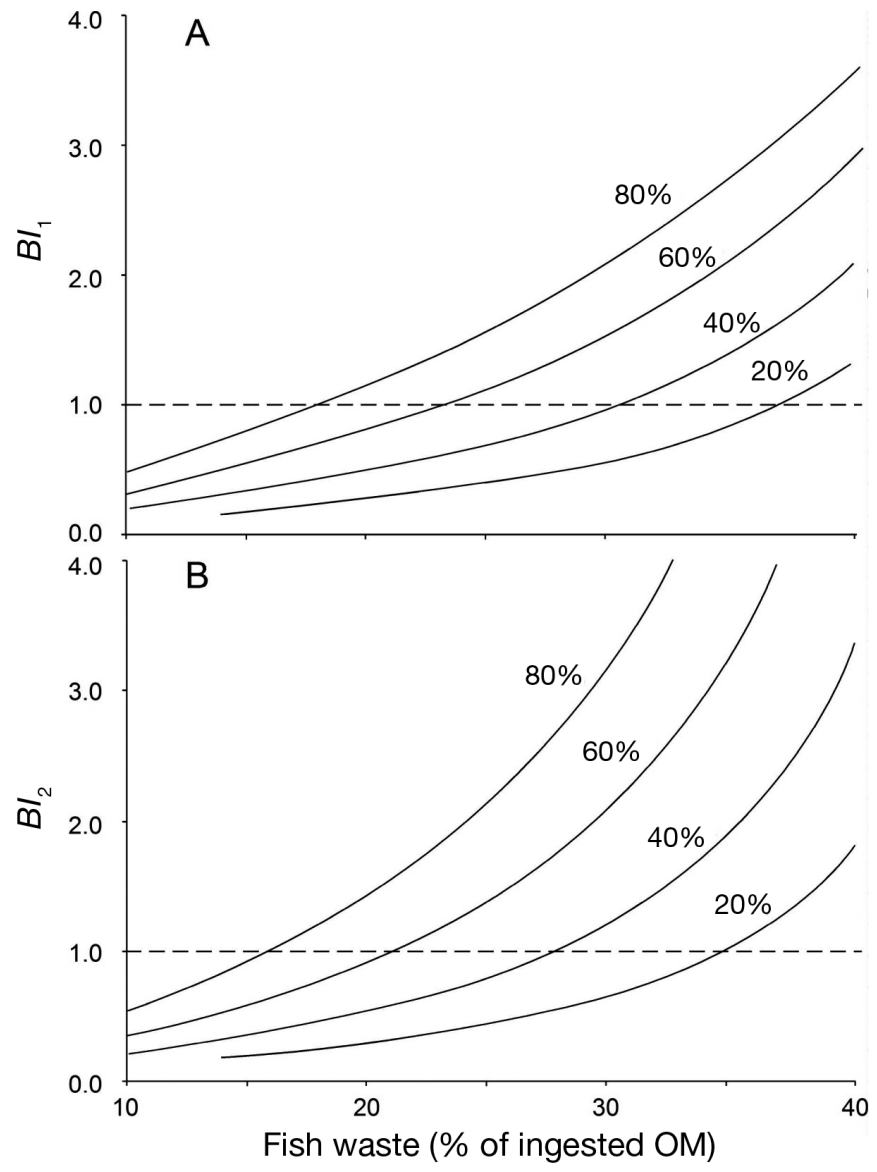

Fig. 3. Relationship between the percentage of fish waste in the mussel diet (ingested organic matter; OM) and the 2 mussel biomitigation indices (see Eqs. 3 \& 4 under 'Biomitigation potential' in the main text). The different lines show results for seston organic content (OC) of 20,40,60, and $80 \%$, assuming an OC of fish waste of $77 \%$ and wastes available to mussels $50 \%$ of the time efficiently absorbed by mussels (Reid et al. 2010). This results in relatively low predicted values for $F_{\mathrm{OF}}$, compared with $F_{\text {OS }}$.

The preceding analysis begs the question whether it is possible for fish feces to supply a substantial fraction of the organic matter ingested by mussels (e.g. $>15$ to $35 \%$; Fig. 3). Mussel diet contributions from net-pens can, to some extent, be inferred from the degree of tissue growth enhancement observed in bivalves at fish farms compared with adjacent control sites. Bivalves cultivated close to open water fish farms have been observed to grow significantly faster than the controls (Jones \& Iwama 1991, Stirling \& Okumus 1995, Lander et al. 2004, 2012, Sarà et al. 2009, Handå et al. 2012a, Jiang et al. 2012). These results contrast with those from other studies that indicate no significant influence on bivalve growth in an integrated system (Taylor et al. 1992, Parsons et al. 2002, Cheshuk et al. 2003, Navarrete-Mier et al. 2010). Although it is difficult to compare these results given the different experimental designs, the observations suggest that fish wastes can comprise an important fraction of the bivalve diet in areas with low seston concentrations and low seston $\mathrm{OC}$, inside or very close to net-pens, in areas where the cultured fish are provided a trash fish diet, and/or during winter at sites outside net-pens when natural food is relatively scarce. Although waste fish feed appears to enhance bivalve tissue growth under these conditions, fish feces alone does not appear to be as effectively utilized by mussels (Both et al. 2012, Handå et al. 2012b).

Another approach to estimating the relative importance of different bivalve nutritional sources at fish farms is based on stable isotope (carbon and nitrogen) analysis of the bivalves, seston, and fish feed and feces. Based on stable carbon isotope analysis, Mazzola \& Sarà (2001) concluded that the role of organic fish wastes in the diet of mussels varied seasonally with an average of $50 \%$ of the diet consisting of fish feed. Sarà et al. (2004) indicated that carbon in fish wastes (feed and feces) contributed $39 \%$ of total particulate organic matter at another Mediterranean fish farm. However, these studies did not specifically quantify fish feces contributions to bivalve diets. Gao et al. (2006) estimated that dietary organic matter available to mussels held inside fish cages, during a period of low phytoplankton availability, consisted of $27.5 \%$ fish feed and $4.2 \%$ fish feces. The remaining fraction was naturally occurring organic matter. This estimated fish feces contribution to the mussel diet is low considering the above predictions that indicate that between 15 and $35 \%$ fish feces organic matter is 
required in the diet for mussels to reduce benthic organic loading from fish feces (Fig. 3).

The preceding analysis indicates that (1) waste feed fines likely do not contribute to local benthic organic enrichment impacts at fish farms unless they are incorporated into larger particles such as mussel fecal pellets, and (2) fish feces may not generally constitute a large enough fraction of the diet to allow mussels to extract more organic matter from fish feces than they release as waste (undigested OFF and/or seston). Both conclusions raise questions about the possible effects of mussel feces production. The organic enrichment effects of organic biodeposition by commercial mussel culture operations have been reviewed on several occasions and tend to be either negligible or localized (e.g. Burkholder \& Shumway 2011, McKindsey et al. 2011). Larger-scale adverse impacts have been observed under site-specific conditions of relatively poor water flushing, high culture density, shallow water, and/or the presence of additional sources of organic enrichment (Hargrave et al. 2008a, Cranford et al. 2009). Given that the mussel component of an open water IMTA system requires high culture densities in an extensive arrangement to be partially effective at capturing all of the suspended wastes (see above), the possible cumulative effects of organic biodeposition from both the fed fish and the organic extractive IMTA components need to be carefully considered.

A preliminary analysis of the possible magnitude of mussel biodeposition at an IMTA site was conducted by calculating mussel organic egestion rates for a

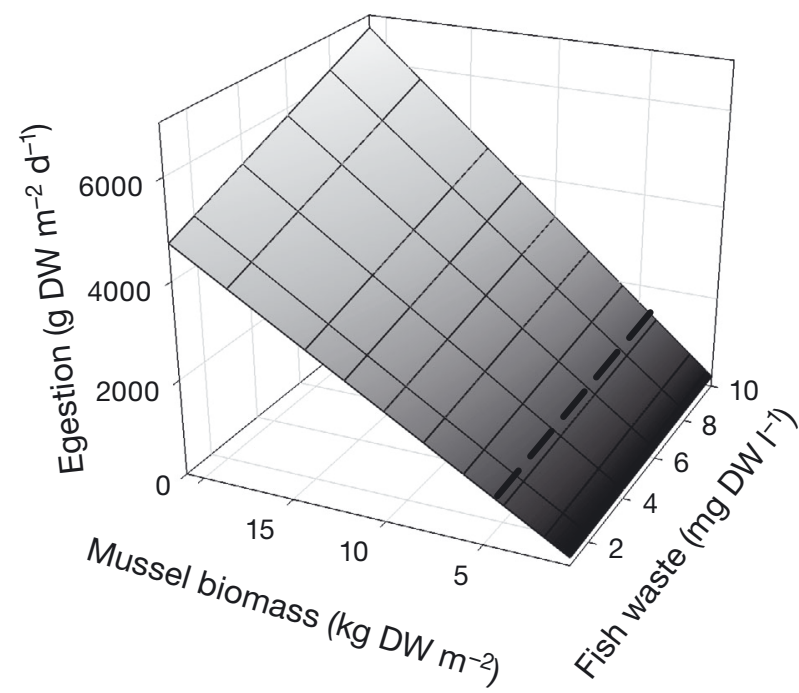

range of depth-integrated mussel stocking densities (1000 to 30000 mussels $\mathrm{m}^{-2}$ of water column or 0.7 to $21 \mathrm{~kg}$ dry tissue $\mathrm{m}^{-2}$ ). In this example, average dietary conditions were based on observations at commercial IMTA sites in the Bay of Fundy. The range of crop densities was derived assuming that mussel droppers were between 5 and $15 \mathrm{~m}$ long (the latter is a typical depth of a salmon net-pen) with 200 to 1000 mussels $\mathrm{m}^{-1}$ of dropper and 1 or 2 droppers $\mathrm{m}^{-2}$. Presently, the mussel stocking biomass at Bay of Fundy sites is approximately $4.3 \mathrm{~kg} \mathrm{DW} \mathrm{m}{ }^{-2}$, with droppers extending from the surface to between 7 and $13 \mathrm{~m}$ depth. Seston concentration was set at $3 \mathrm{~g}$ DW $\mathrm{m}^{-3}$ with $36 \%$ OC (Reid et al. 2010). Fish feces was assumed to be available to mussels $50 \%$ of the time and ranged from 1 to $10 \mathrm{~g} \mathrm{DW} \mathrm{m}^{-3}$ with $86 \%$ OC (1:1 mix of fish feed fines and feces). Absorption efficiency was assumed to be $88 \%$ for this mix of OFF (Reid et al. 2010) and 39\% for seston (Eq. 4). Organic matter in mussel feces was assumed to be $5 \%$ carbon (Smaal \& Zurburg 1997). Total DW and carbon egestion rates were calculated for comparison with results from previous model predictions.

The calculated egestion rate of an individual mussel feeding only on the available seston was $83 \mathrm{mg}$ DW $\mathrm{d}^{-1}$, which is within the range of field observations (Cranford \& Hill 1999, Callier et al. 2006, Weise et al. 2009). Population egestion rates are summarized in Fig. 4 for the described IMTA scenarios, and feces production is predicted to reach a maximum of $6735 \mathrm{~g} \mathrm{DW} \mathrm{m}^{-2} \mathrm{~d}^{-1}$ or $102 \mathrm{~g} \mathrm{C} \mathrm{m}^{-2} \mathrm{~d}^{-1}$ at the highest stocking densities and waste concentrations investi-

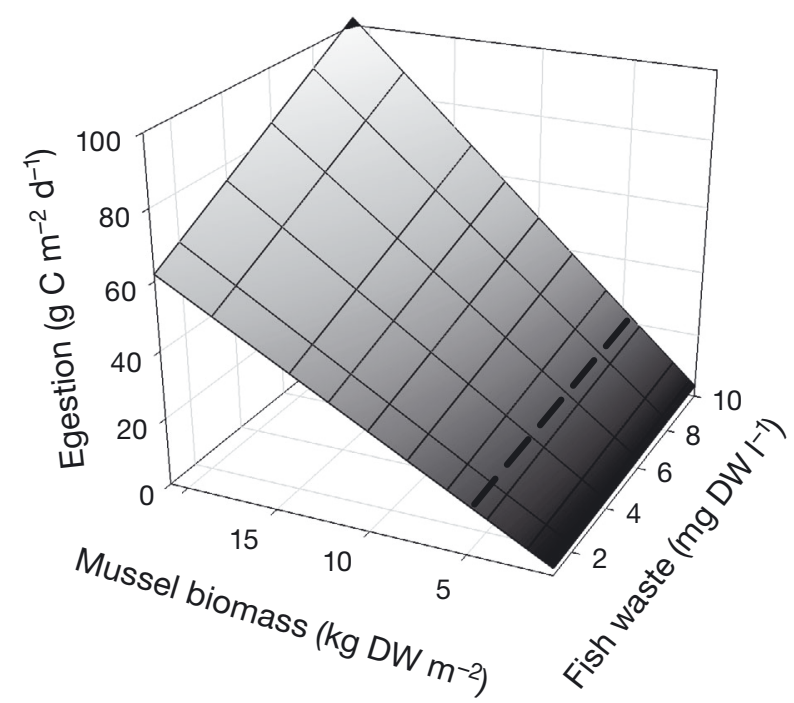

Fig. 4. Estimated total dry weight (DW; left plot) and carbon (right) egestion rates for ranges of depth-integrated mussel stocking biomass (tissue DW) and suspended fish waste concentrations. The dashed lines show results for typical mussel densities at commercial Integrated Multi-Trophic Aquaculture farms in the Bay of Fundy, Canada. Calculation details are provided under 'Biomitigation potential' in the main text 
gated (Fig. 4). Current mussel stocking densities in the Bay of Fundy are estimated to produce 13 to $19 \%$ of these values (Fig. 4). Given that mussel stocking levels (seeding density per dropper, droppers per area, and/or dropper length) would need to be increased markedly to improve waste particle capture in the future, the maximum predicted egestion rates are used in the following discussion. Egestion rates cannot be interpreted as representing benthic loading (deposition rate) owing to the expected horizontal spreading of fecal pellets during sedimentation to the seabed. Average settling velocities of 1.0 and $3.2 \mathrm{~cm} \mathrm{~s}^{-1}$ for mussel and salmon feces, respectively (Reid et al. 2009, Weise et al. 2009), indicate that the mussel biodeposits would generally spread over a larger area of seabed than do salmon feces. Modeling approaches have been developed for predicting benthic fecal loading from both fish and shellfish aquaculture operations (Cromey et al. 2002, Weise et al. 2009). Benthic community alterations have been observed at deposition rates greater than $15 \mathrm{~g}$ DW $\mathrm{m}^{-2} \mathrm{~d}^{-1}$ (Weise et al. 2009) and $1 \mathrm{~g} \mathrm{C} \mathrm{m}^{-2} \mathrm{~d}^{-1}$ (Chamberlain \& Stucchi 2007), and both thresholds would be exceeded if just $1 \%$ of the mussel egestion flux predicted for the highest densities reached the seabed. A significant decrease in all macrofauna is predicted when benthic carbon loading exceeds $5 \mathrm{~g}$ $\mathrm{C} \mathrm{m}^{-2} \mathrm{~d}^{-1}$ (Hargrave et al. 2008b), a level that would be exceeded if approximately $5 \%$ of the predicted mussel egestion flux deposited on the seabed.

These results accentuate the importance of designing IMTA systems in such a way that a significant proportion of the mussel diet is comprised of organics from the fish farm ( $>15$ to $30 \%$, depending on the site). In an IMTA situation where there will be organic loading coming from the fish component, avoiding an increase in benthic loading will be important. This will mean optimizing the number of mussels and their relative positions with respect to the fish farm so that they extract the maximum amount of fish farm organics while not increasing the benthic load.

\section{BALANCING THE ECONOMIC AND BIOMITIGATION ROLES OF EXTRACTIVE SPECIES}

The underlying philosophy of open water IMTA is to decrease the known environmental effects of fed fish culture through the creation of trophic linkages while also increasing the profitability of a farmed area. The profitability objective could place an addi- tional constraint on the efficiency of organic extractive species to recycle particulate wastes, as illustrated in Fig. 5. The maximum production of an organic extractive species crop at any given site is limited by food availability, and this is the basis of the production carrying capacity concept (e.g. Grant \& Filgueira 2011). Food depletion by mussels acts as a biological feedback mechanism that limits mussel production (e.g. Rosland et al. 2011). Maximum crop production for a given area is reached when the rate processes that supply food to the culture are in balance with the rate of food removal by the crop. This carrying capacity of a site represents the production that may be achieved given temporal variability in stocking biomass and environmental processes over the production cycle. Increasing crop biomass beyond this carrying capacity causes food depletion and diminishing crop production (Fig. 5). To achieve the highest degree of waste extraction, a stocking biomass is required that exceeds production carrying capacity and which consequently results in relatively low crop production (Point $\mathrm{C}$ in Fig. 5). Assuming that efficient fish waste extraction is one of the primary roles of an IMTA system, a farm design that is efficient at capturing waste particulate matter will

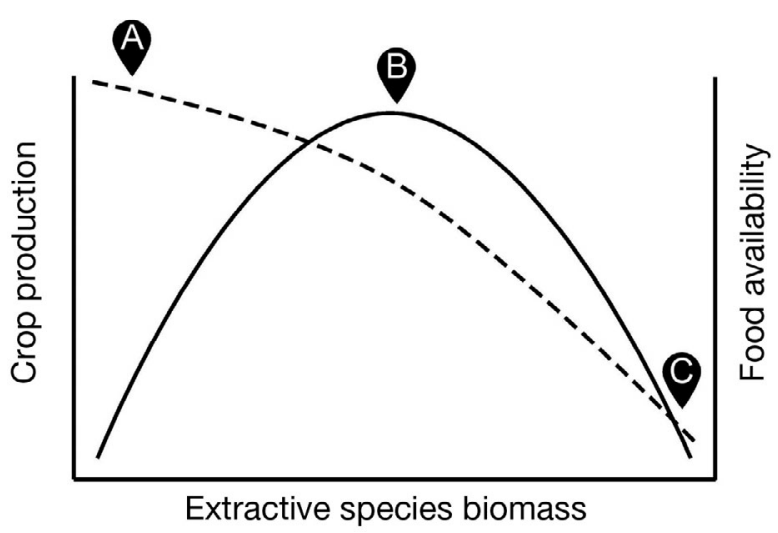

Fig. 5. Conceptual diagram of the effects of increasing extractive species biomass on integrated multi-trophic aquaculture (IMTA) farm profitability (crop production) and sustainability (availability of particulate organic fish waste, OFW). Point A represents existing open water IMTA farm conditions, at which the relatively low biomass of extractive species results in sub-maximal crop production (solid line) and low OFW depletion (dashed line). Point B corresponds with the production carrying capacity of the extractive species, which occurs when crop production is limited by the available food supply, including OFW. At Point C, the high stocking biomass provides efficient waste extraction at the expense of crop production and profitability. The OFW availability line is shown as a curve owing to the expected feedback effects of increasing IMTA structures on current speed reduction and the resulting increase in particle capture efficiency 
likely cause food limitation, with the result that crop production is less than could be achieved at a stocking biomass that is more in balance with food availability. Additional grow-out time may then be required for the extractive species to reach an acceptable market size. Alternatively, an IMTA farmer may decide to control the balance between profitability and fish waste extraction efficiency by altering the density of the extractive species.

\section{CONCLUSIONS}

The above analysis of potential limitations on organic fish waste recycling by mussels within open water IMTA systems confirms, and expands on, previous concerns expressed on the implementation of systems employing bivalves as the sole organic extractive species (Troell \& Norberg 1998, Cheshuk et al. 2003, Navarrete-Mier et al. 2010). Open water integrated fish-mussel aquaculture systems currently in operation and development may be expected to remove only a small fraction of the particulate wastes from the fed fish component owing to the relatively low mussel densities employed, their location in the upper water column away from the primary source of particulate waste (fish feces), the orientation of the bivalves relative to directional flow variation, and the size-class distribution of the particulates. Engineering advances in both structural design and improved linkages with water flow may increase efficiency. Positioning shellfish structures at a central location surrounded by fish net-pens would increase shellfish exposure to wastes over a large percentage of the tidal cycle, but such an arrangement may impose space limitation for mussel structures, and solid wastes exiting individual fish pens would not pass any of the shellfish for large parts of the tidal cycle. The present orientation of mussel structures appears to primarily target fish feed 'fines' that do not cause any known benthic organic enrichment impact, but which can enhance mussel growth under some conditions. Open water OFW extraction by mussels, and other filter-feeders, is primarily limited by the time available to intercept and capture particles. This can only be partially compensated by employing intensive (biomass) and extensive (space) mussel culture structures. Under such conditions, capture efficiencies on the order of $50 \%$ may be possible under ideal conditions at sites with relatively low current speeds $\left(\sim 2 \mathrm{~cm} \mathrm{~s}^{-1}\right)$, but would be difficult to achieve at higher flows (Fig. 1).

For the IMTA concept to be valid, the suspension feeder component would have to produce feces con- taining less organic matter from the natural seston than contained in the organic matter from the fish feces absorbed. This should not be assumed for any site given that the primary food source of these animals occurs naturally and will contribute to organic loading. Environmental conditions that are best suited to IMTA with mussels include areas where fish wastes dominate naturally occurring particulate food resources and where a high fraction of the seston organic matter is absorbed by the mussels.

IMTA is meant to promote economic and environmental sustainability. However, an appropriate balance between the environmental and financial objectives of IMTA needs to be found considering that waste extraction efficiency, food depletion (fish wastes and naturally available sources) and crop production are interrelated and controlled by the farmer. Farmers may benefit from the willingness of consumers to pay a price premium for IMTA products (e.g. ecolabeling). Indications of consumer preference for IMTA products have come from public attitudinal studies in which the waste extraction benefits of IMTA were described in basic terms (Ridler et al. 2006, 2007, Barrington et al. 2010). Given that waste recycling in open water systems containing filterfeeders as the sole organic extractive species appears to be less efficient than required to meet basic IMTA descriptions, future open water IMTA research should focus on the development of systems that rely to a much greater extent on extractive species held in structures designed to better capture and accumulate organic wastes. The development of a benthic component, comprised of deposit feeders that will have access to the vertical flux of particles from fish netpens, is an important stage in the development of IMTA systems.

IMTA has been defined using subjective terms related to possible social and environmental benefits. The lack of a quantitative definition makes it difficult to evaluate whether IMTA is meeting stakeholder expectations. This paper has focused on identifying critical limitations on organic fish waste extraction efficiency by mussels. The identification of these limitations should not be interpreted as a judgment on the effectiveness of IMTA systems as a whole. It may be possible to design systems that address inefficiencies in, or impacts from, one component through the addition of other extractive species. Also, some ecological benefits may be achieved under conditions of low waste extraction efficiency. These benefits require further study at open water sites so that the capabilities of IMTA may be better defined and evaluated. 
Acknowledgements. This work was supported by the Department of Fisheries and Oceans Canada and the Natural Sciences and Engineering Research Council of Canada through contributions to the strategic Canadian Integrated Multi-Trophic Aquaculture Network. Additional support was provided by Research Council of Norway contributions to the EXPLOIT project (Exploitation of Nutrients from Salmon Aquaculture). The authors thank Ø. Strand and R. Filgueira for constructive comments on the manuscript and appreciate the contributions of 3 anonymous reviewers.

\section{LITERATURE CITED}

Barrington K, Ridler N, Chopin T, Robinson S, Robinson B (2010) Social aspects of the sustainability of integrated multi-trophic aquaculture. Aquacult Int 18:201-211

$>$ Bayne BL, Hawkins AJS, Navarro E (1987) Feeding and digestion by the mussel Mytilus edulis L. (Bivalvia: Mollusca) in mixtures of silt and algal cells at low concentrations. J Exp Mar Biol Ecol 111:1-22

Both A, Parrish CC, Penney RW (2012) Growth and biochemical composition of Mytilus edulis when reared on effluent from a cod, Gadus morhua, aquaculture facility. J Shellfish Res 31:79-85

Burkholder JN, Shumway SE (2011) Bivalve shellfish aquaculture and eutrophication. In: Shumway SE (ed) Shellfish aquaculture and the environment. John Wiley \& Sons, Chichester, p 155-215

Callier MD, Weise AM, McKindsey CW, Desrosiers G (2006) Sedimentation rates in a suspended mussel farm (GreatEntry Lagoon, Canada): biodeposit production and dispersion. Mar Ecol Prog Ser 322:129-141

Chamberlain J, Stucchi D (2007) Simulating the effects of parameter uncertainty on waste model predictions of marine finfish aquaculture. Aquaculture 272:296-311

Cheshuk BW, Purser GJ, Quintana R (2003) Integrated open-water mussel (Mytilus planulatus) and Atlantic salmon (Salmo salar) culture in Tasmania, Australia. Aquaculture 218:357-378

> Chopin T, Buschmann AH, Halling C, Troell M and others (2001) Integrating seaweeds into marine aquaculture systems: a key towards sustainability. J Phycol 37: 975-986

Cranford PJ, Hill PS (1999) Seasonal variation in food utilization by the suspension-feeding bivalve molluscs Mytilus edulis and Placopecten magellanicus. Mar Ecol Prog Ser 190:223-239

Cranford PJ, Hargrave BT, Doucette LI (2009) Benthic organic enrichment from suspended mussel (Mytilus edulis) culture in Prince Edward Island, Canada. Aquaculture 292:189-196

Cranford PJ, Ward JE, Shumway SE (2011) Bivalve filter feeding, variability and limits of the aquaculture biofilter. In: Shumway SE (ed) Shellfish aquaculture and the environment. John Wiley \& Sons, Chichester, p 81-112

Cromey CJ, Nickell TD, Black KD (2002) DEPOMOD modelling the deposition and biological effects of waste solids from marine cage farms. Aquaculture 214:211-239

Dame RF (2011) Ecology of marine bivalves: an ecosystem approach. CRC Press, Boca Raton, FL

> Davenport J, Smith RJJW, Packer M (2000) Mussels Mytilus edulis: significant consumers and destroyers of mesozooplankton. Mar Ecol Prog Ser 198:131-137

Figueiras FG, Labarta U, Fernández Reiriz MJ (2002)
Coastal upwelling, primary production and mussel growth in the Ria Baixas of Galicia. Hydrobiologia 484: 121-131

> Gao QF, Shin PKS, Lin GH, Chen SP, Cheung SG (2006) Stable isotope and fatty acid evidence for uptake of organic waste by green-lipped mussels Perna viridis in a polyculture fish farm system. Mar Ecol Prog Ser 317:273-283

Grant J, Filgueira R (2011) The application of dynamic modelling to prediction of production carrying capacity in shellfish farming. In: Shumway SE (ed) Shellfish aquaculture and the environment. John Wiley \& Sons, Chichester, p 135-154

> Grant J, Bacher C, Cranford PJ, Guyondet T, Carreau M (2008) A spatially explicit ecosystem model of seston depletion in dense mussel culture. J Mar Syst 73:155-168

Handå A, Min H, Wang X, Broch OJ, Reitan KI, Reinertsen H, Olsen Y (2012a) Incorporation of fish feed and growth of blue mussels (Mytilus edulis) in close proximity to salmon (Salmo salar) aquaculture: implications for integrated multi-trophic aquaculture in Norwegian coastal waters. Aquaculture 356-357:328-341

> Handå A, Ranheim A, Olsen AJ, Altin D, Reitan KI, Olsen Y, Reinertsen $H$ (2012b) Incorporation of salmon fish feed and feces components in mussels (Mytilus edulis): implications for integrated multi-trophic aquaculture in Norwegian coastal waters. Aquaculture 370-371:40-53

> Hargrave BT, Doucette LI, Cranford PJ, Law BA, Milligan TG (2008a) Influence of mussel aquaculture on sediment organic enrichment in a nutrient-rich coastal embayment. Mar Ecol Prog Ser 365:137-149

Hargrave BT, Holmer M, Newcombe CP (2008b) Towards a classification of organic enrichment in marine sediments based on biogeochemical indicators. Mar Pollut Bull 56: 810-824

Hawkins AJS, Bayne BL, Bougrier S, Héral M and others (1998) Some general relationships in comparing the feeding physiology of suspension-feeding bivalve molluscs. J Exp Mar Biol Ecol 219:87-103

Hawkins AJS, James MR, Hickman RW, Hatton S, Weatherhead M (1999) Modelling of suspension-feeding and growth in the green-lipped mussel Perna canalicus exposed to natural and experimental variations of seston availability in the Marlborough Sounds, New Zealand. Mar Ecol Prog Ser 191:217-232

> Jiang Z, Wang G, Fang J, Mao Y (2012) Growth and food sources of Pacific oyster Crassostrea gigas integrated culture with sea bass Lateolabrax japonicus in Ailian Bay, China. Aquacult Int 21:45-52

Jones TO, Iwama GK (1991) Polyculture of the Pacific oyster, Crassostrea gigas (Thunberg), with chinook salmon, Oncorhynchus tshawytscha. Aquaculture 92:313-322

Lander T, Barrington K, Robinson S, MacDonald B, Martin J (2004) Dynamics of the blue mussel as an extractive organism in an integrated multi-trophic aquaculture system. Bull Aquacult Assoc Can 104:19-28

> Lander TR, Robinson SMC, MacDonald BA, Martin JD (2012) Enhanced growth rates and condition index of blue mussels (Mytilus edulis) held at integrated multitrophic aquaculture (IMTA) sites in the Bay of Fundy. J Shellfish Res 31:997-1007

> MacDonald BA, Robinson SMC, Barrington KA (2011) Feeding activity of mussels (Mytilus edulis) held in the field at an integrated multi-trophic aquaculture (IMTA) site (Salmo salar) and exposed to fish food in the laboratory. Aquaculture 314:244-251 
Mazzola A, Sarà G (2001) The effect of fish farming organic waste on food availability for bivalve molluscs (Gaeta Gulf, Central Tyrrhenian, MED): stable carbon isotope analysis. Aquaculture 192:361-379

McKindsey CW, Archambault P, Callier MD, Olivier F (2011) Influence of suspended and off-bottom mussel culture on the sea bottom and benthic habitats: a review. Can J Zool 89:622-646

Navarrete-Mier F, Sanz-Lázaro S, Marin A (2010) Does bivalve mollusc polyculture reduce marine fin fish farming environmental impact? Aquaculture 306:101-107

- Navarro E, Iglesias JIP, Camacho AP, Labarta U, Beiras R (1991) The physiological energetics of mussels (Mytilus galloprovincialis Lmk) from different cultivation rafts in the Ria de Arosa (Galicia, N.W. Spain). Aquaculture 94: 197-212

> Navarro E, Iglesias JIP, Camacho AP, Labarta U (1996) The effect of diets of phytoplankton and suspended bottom material on feeding and absorption of raft mussels (Mytilus galloprovincialis Lmk). J Exp Mar Biol Ecol 198: 175-189

Page FH, Losier R, McCurdy P, Greenberg D, Chaffey J, Chang B (2005) Dissolved oxygen and salmon cage culture in the southwestern New Brunswick portion of the Bay of Fundy. Handb Environ Chem 5M:1-28

Parsons GJ, Shumway SE, Kuenstner S, Gryska A (2002) Polyculture of sea scallops (Placopecten magellanicus) suspended from salmon cages. Aquacult Int 10:65-77

Reid GK, Liutkus M, Robinson SMC, Chopin T and others (2009) A review of the biophysical properties of salmonid faeces: implications for aquaculture waste dispersal models and integrated multi-trophic aquaculture. Aquacult Res 40:257-273

Reid GK, Liutkus M, Bennett A, Robinson SMC, MacDonald B, Page F (2010) Absorption efficiency of blue mussels (Mytilus edulis and M. trossulus) feeding on Atlantic salmon (Salmo salar) feed and fecal particulates: implications for integrated multi-trophic aquaculture. Aquaculture 299:165-169

Remen M, Oppedal F, Torgersen T, Imsland AK, Olsen RE (2012) Effects of cyclic environmental hypoxia on physiology and feed intake of post-smolt Atlantic salmon: initial responses and acclimation. Aquaculture 326-329:148-155

Ridler N, Robinson B, Chopin T, Robinson S, Page F (2006) Development of integrated multi-trophic aquaculture in the Bay of Fundy, Canada: a socio-economic case study. World Aquacult 37:43-48

Ridler N, Wowchuk M, Robinson B, Barrington K and others

Editorial responsibility: Kenneth Black, Oban, UK
(2007) Integrated multi-trophic aquaculture (IMTA): a potential strategic choice for farmers. Aquacult Econ Manag 11:99-110

> Rosland R, Bacher C, Strand Ø, Aure J, Strohmeier T (2011) Modelling growth variability in longline mussel farms as a function of stocking density and farm design. J Sea Res 66:318-330

> Sarà G, Scilipoti D, Mazzola A, Modica A (2004) Effects of fish farming waste to sedimentary and particulate organic matter in a southern Mediterranean area (Gulf of Castellammare, Sicily): a multiple stable isotope study $\left(\delta^{13} \mathrm{C}\right.$ and $\left.\delta^{15} \mathrm{~N}\right)$. Aquaculture 234:199-213

Sarà G, Zenone A, Tomasello A (2009) Growth of Mytilus galloprovincialis (Mollusca, Bivalvia) close to fish farms: a case study of integrated multi-trophic aquaculture within the Tyrrhenian Sea. Hydrobiologia 636:129-136

Smaal AC, Zurburg W (1997) The uptake and release of suspended and dissolved material by oysters and mussels in Marennes-Oléron Bay. Aquat Living Resour 10:23-30

Soto D (2009). Integrated mariculture: a global review. FAO Fisheries and Aquaculture Technical Paper 529. FAO, Rome

> Stirling HP, Okumus I (1995) Growth and production of mussels (Mytilus edulis L.) suspended at salmon cages and shellfish farms in two Scottish sea lochs. Aquaculture 134:193-210

Strohmeier T, Aure J, Duinker A, Castberg T, Svardal A, Strand $\varnothing$ (2005) Flow reduction, seston depletion, meat content and distribution of diarrhetic shellfish toxins in a long-line blue mussel (Mytilus edulis) farm. J Shellfish Res 24:15-23

Taylor BE, Jamieson G, Carefoot TH (1992) Mussel culture in British Columbia: the influence of salmon farms on growth of Mytilus edulis. Aquaculture 108:51-66

Troell M, Norberg J (1998) Modelling output and retention of suspended solids in an integrated salmon-mussel culture. Ecol Model 110:65-77

> Troell M, Halling C, Neori A, Chopin T, Buschmann AH, Kautsky N, Yarish C (2003) Integrated mariculture: asking the right questions. Aquaculture 226:69-90

- Ward JE, Shumway SE (2004) Separating the grain from the chaff: particle selection in suspension- and deposit-feeding bivalves. J Exp Mar Biol Ecol 300:83-130

Weise AM, Cromey CJ, Callier MD, Archambault P, Chamberlain J, McKindsey CW (2009) Shellfish-DEPOMOD: modelling the biodeposition from suspended shellfish aquaculture and assessing benthic effects. Aquaculture 288:239-253

Submitted: February 15, 2013; Accepted: June 17, 2013 Proofs received from author(s): July 17, 2013 